\title{
El teatro en La Paz a fines del siglo XVIII y el proyecto de la Ilustración
}

\author{
The theatre in La Paz at the end of the 18th century \\ and the Enlightenment project \\ Andrés Eichmann Oehrli \\ Universidad Mayor de San Andrés- Bolivia \\ apeichmann@gmail.com
}

\section{Resumen}

Es muy escasa la información que tenemos sobre la práctica teatral a finales del siglo XVIII en La Paz. Me propongo dar cuenta de algunos hallazgos relacionados con ella, a la vez que mostrar, con los datos a disposición, que esta actividad estuvo ligada a las expectativas de las élites ilustradas, que consideraban el teatro, junto la escuela, como un medio de educación. A través del teatro se buscaba inculcar el buen gusto y el decoro, y orientar la conducta del pueblo hacia la virtud y la obediencia a la autoridad. Precisamente, se podrán ver ejemplos que muestran esta intencionalidad, en particular una pieza teatral compuesta en La Paz en 1786. Esta se pondrá en diálogo con dos escritos destinados a la educación, salidos de la pluma del arzobispo José Antonio de San Alberto en la década de 1780, inspirados en el regalismo fidelista de Bossuet. Asimismo podrá observarse la sintonía de ambos géneros con un poema que integró las celebraciones populares de La Paz con ocasión de la jura al cautivo rey Fernando VII en 1808.

Palabras claves: Charcas - La Paz - Teatro - Ilustración- Siglo XVIII - Educación Política

\begin{abstract}
We have very little information about the theatrical practice in La Paz at the end of the 18th century. I intend to give an account of some findings related to this matter, while showing, based on the avalaible data, that this activity was linked to the expectations of the enlightened elites, who considered theatre, along with school, as a means of education. Through the theatre they sought to inculcate good taste and decorum, and to orient the people's conduct towards virtue and obedience to authority. Precisely, it will be able to see examples that show this intention, in particular a theatrical piece composed in La Paz in 1786. This will be put into dialogue with two writings destined for education, coming from the pen of Archbishop José Antonio de San Alberto in the 1780s, inspired by the fidelist regalism of Bossuet. Likewise, the harmony of both genres can be observed with poem that integrated the popular celebrations of La Paz on the occasion of the oath to the captive King Fernando VII in 1808.
\end{abstract}


Key words: Charcas - La Paz - Theater - Enlightenment culture - 18th century - Political Education

Recibido: 29 de mayo de 2020 - Aceptado: 27 de junio de 2020

\section{El primer coliseo de La Paz y la intención de mejorar las costumbres}

El capitán de fragata Fernando de la Sota Agüero ejerció un breve interinato de quince meses (17951796) en el cargo de gobernador intendente de La Paz. En el Diccionario histórico del Departamento de La Paz (Aranzáez ([1915] 2019) se indican muy pocas cosas sobre de la Sota, pero se precisa que su breve mandato concluyó el 11 de septiembre de 1796. En ese corto tiempo llevó a cabo importantes obras públicas con que se ganó la estima de la población influyente. Por tal motivo el ayuntamiento y los vecinos de la ciudad de La Paz hicieron una súplica el 31 de agosto de 1796 para pedir que fuera ratificado en ese cargo en calidad de titular1. En otro expediente ya no es solamente el ayuntamiento paceño quien solicita esto, sino que se suman al pedido la propia "audiencia de Charcas, el obispo [de La Paz], cabildo eclesiástico" (AGI, Charcas, 436, fols. 378 y ss.), y se hace eco el propio virrey. A pesar de ello, la petición no prosperó. En compensación por sus servicios (no solamente los realizados en La Paz) el rey le concedió el hábito de caballero de la orden de Santiago en 1798 (Cárdenas Piedra, 1995: 161-162, núm. 2253).

En estos documentos se encarece que la ciudad, hasta la gestión del capitán de la Sota, se encontraba "arruinada e incendiada de resultas de los dos asedios los más crueles que sufrió en la revolución de los indios del año 1781" (AGI, Estado, 76, núm. 2, fol. 1v.). Se detallan a continuación sus obras: primero, el puente de San Francisco, destruido quince años atrás por la rebelión, "siendo continuo el lamento de aquellos moradores por su falta" (AGI, Charcas, 436, fol. 476r.), y que ahora en muy breve tiempo se había logrado acabar y perfeccionar, siendo "el mejor, más capaz y más sólido en la construcción que los otros que tiene la ciudad" (AGI, Estado, 76, núm. 2, fols. 1v-2r.). Segundo, el establecimiento del sistema de alumbrado y serenos, que se hizo con «faroles aseados y primorosos de cristal», y se estima que "es una obra peregrina hasta el día, porque no la tiene igual ni semejante ninguna de las ciudades del Perú" (AGI, Estado, 76, núm. 2, fol. 2r.). Se conserva un plano de la ciudad de La Paz, hecho por orden de de la Sota para disponer el alumbrado público. Puede verse, en una reproducción que se encuentra en el último anexo de Diez de Medina (1994), que el coliseo figura en el número 25 del cuadro que lleva por rótulo "EXPLYCACYON". Este doble sistema se considera un "precioso arbitrio de policía [que] contiene los desórdenes nocturnos" (AGI, Charcas, 436, fol. 476r.). El tercer logro es

el coliseo de comedias, que jamás le hubo, construido, plantificado y aperado decentemente con general aplauso; y el objeto regular de pintar los vicios, corregir las costumbres corrompidas y los abusos, y evitar los crímenes nocturnos con lo honesto 
de este entretenimiento, con que está muy bien hallado el pueblo (AGI, Estado, 76, núm. 2, fol. 2r.).

A finales del siglo XIX Nicolás Acosta, con la habitual arrogancia hacia el pasado que parece una constante en nuestro medio (e introduciendo una imprecisión que delata su falta de noticias) afirma que "[e]l primer teatro fue construido grotescamente a mediados del siglo pasado [es decir el XVIII] en el lugar que hoy ocupa la casa de los señores Macías (Calle del Mercado)". Cree que no había afición al teatro en esta ciudad. Después de confesar que no posee datos de cuándo se representaron las primeras «comedias y tragedias», sostiene que en el siglo XVIII "solo se exhibían loas" (Acosta, 1880: 67). Volvamos ahora a la realidad.

Basta lo leído hasta aquí para verificar que de la Sota compartía las inquietudes de los funcionariosilustrados, acordes con el perfil con que estos eran seleccionados en la metrópoli. Para que se entienda mejor esta afirmación es preciso decir qué debe entenderse como perfil del funcionario ilustrado, y para ello remito a un trabajo de Josep M. Barnadas (2010), quien comienza alertando sobre el carácter "históricamente análogo" del concepto 'Ilustración'. "Esto significa que dicho concepto puede adquirir rasgos y tendencias parcialmente diferentes según momentos, lugares, grupos y aun individuos" (Barnadas, 2010: 23). La Ilustración en América, que no puede desvincularse del "programa reformista de[1] gobierno borbónico" (Barnadas, 2010: 24), trajo consigo algunas tendencias que tendrán sus manifestaciones en los funcionarios encargados de llevarlas a la práctica. Entre los rasgos que enumera se encuentra la «aceptación del deber de perseguir el bienestar de los súbditos, lo que hace priorizar el conocimiento práctico/aplicable sobre el especulativo»; y señala, entre las tendencias y aspiraciones de algunos ilustrados, la "aceptación del paradigma que cree en la 'felicidad humana' (ideal hasta entonces implícito, pero que se hace explícito y “plausible')" y el "reconocimiento de la 'diversidad' humana y de la historicidad de su desarrollo" (Barnadas, 2010: 24).

En efecto, a de la Sota lo vemos interesado por el orden de la ciudad, por su progreso, y por todo lo que pudiera darle mayor lustre o contribuir a la 'felicidad' de sus vecinos, y en la necesidad de medidas prácticas al servicio de tales objetivos. Los firmantes, por su parte, constituyen un público que también manifiesta entusiasmo por la gestión del gobernador intendente.

En los textos citados se vincula la utilización del coliseo con el mejoramiento de las costumbres (gracias a la representación de los vicios en la escena) y con la disminución de los crímenes nocturnos. Suponemos que antes de la construcción del coliseo habría un corral de comedias, tan familiares en toda ciudad hispana y también americana; no tenemos por ahora ninguna noticia al respecto, pero su ausencia en La Paz sería sorprendente. En textos de la época suele considerarse el coliseo como el escalón superior al que debe arribar la expresión teatral, una vez superada la manifestación popular propia del corral. En 1763 Nipho y Cagigal "propone un tránsito para que el teatro, desde los "principios de corral" de comedias, "aspire a los honores de coliseo" (Vieites, 2019: 211). No 
he podido consultar todavía las actas del cabildo para encontrar posibles noticias sobre un corral2 ${ }^{2}$.

Uno de los documentos da algunas luces más sobre el motivo que llevó a construir el coliseo, porque permite saber al menos una de las "costumbres corrompidas" a las que se refería el arriba citado. Se dice que de la Sota,

[c]onociendo [...] las ruinas que causaba el pernicioso vicio de los juegos de envite, procuró con el rigor preciso y el consejo prudente exterminarlo. Pero como en los países de numerosa población sea máxima política establecer objetos que entretengan a toda especie de gentes, meditó [...] que un coliseo de comedias sería el firme apoyo de sus consuelos y más decente entretenimiento. Logró en fin sus ideas, y al cambio de un vicio de destrucción estableció el más honesto y menos ruinoso a aquellos moradores (AGI, Charcas, 436, fol. 476v 477r.).

Es decir, volvemos a la preocupación por el orden, esta vez en otras de sus facetas. En parte se trata de combatir el juego, que parece considerarse ligado a la frecuencia de "crímenes nocturnos", y que en cualquier caso producía descalabros económicos entre los vecinos. Pues bien, el gobernador decidió librar la batalla no solamente con medidas coactivas (que no se especifican aquí) sino también ofreciendo como alternativa un entretenimiento atractivo que pudiera ser acogido "a cambio".

Puede valer la pena reparar en el motivo por el que las autoridades municipales del Cusco, en el primer tercio del siglo XVII, decidieron poner en marcha la construcción de un recinto para la actividad teatral. Leemos en la obra anónima (que con buen olfato Ricardo Palma considera atribuible a algún canónigo del Cusco de mediados del siglo XVIII) titulada Anales del Cuzco (1901: 46): "acordó el cabildo, para recreo y diversión de la república y para evitar ofensas a Dios era conveniente se hiciese un corral de comedias o coliseo [...]. Lo mismo se trató por muchas otras actas, y se fabricó el coliseo" 3 . El "recreo y diversión" que expresa este documento es equivalente al citado de La Paz, que indica el beneficio de "establecer objetos que entretengan", mientras que "evitar ofensas a Dios" es reemplazado en tiempos ilustrados por la apelación a la "decencia" y a medidas políticas tendientes a evitar crímenes.

\section{Teatro y educación (también política)}

Ya desde la antigua Grecia, el teatro era concebido como algo más que mero entretenimiento. Era un medio para educar a la población, a menudo para suscitar reflexiones en torno a problemas morales, a la vida en sociedad y a la política. La Ilustración también lo entendió así. Manuel Vieites muestra un buen número de pensadores ilustrados españoles que participaron en un intenso debate acerca de lo que debía esperarse del teatro y de su "reforma", que debía abarcar la materialidad del espacio teatral y también el repertorio. Desde la Poética de Luzán (1737) se produce una abundante literatura teórica y se emitieron normas, también abundantes. Además, se registran obras dramáticas en las que sus autores buscaron llevar a la práctica el ideario ilustrado. Hay quienes 
situaron el teatro en el mismo rango que la escuela, al punto de que se buscaba postular una organización teatral, como disciplina que incluyera la formación de los poetas dramáticos y la educación de los actores para llegar a la educación del público, a la par de la (también incipiente) organización escolar (Vieites, 2019: 212). Cita Vieites un escrito de Mariano Luis de Urquijo, del año 1791, según el cual así como se deben seleccionar bien las lecturas para que los niños de la escuela adquieran un lenguaje apropiado, buen gusto y para que estén alejados de "credulidades nocivas", también se debe atender con el mismo desvelo el teatro, donde aprenden los ciudadanos "a ser útiles al Estado, hombres de bien, de probidad, a formar sus costumbres, y a ser celosos ciudadanos por el bien de la Patria" (Vieites, 2019, 212).

Veamos ahora si podemos poner estas expectativas en relación con el escasísimo material teatral de esa época que se conserva en La Paz.

\section{a. La loa a Segurola}

La única obra compuesta en La Paz cuyo texto está a nuestra disposición es una loa que se atribuyó a Pedro Nolasco Crespo, pero que habría sido compuesta por Jacinto Roque de Liévana, funcionario (al igual que Crespo) de las Cajas Reales ${ }^{4}$. La loa, que habría sido encargada a Liévana por Crespo, se representó en la plaza mayor en honor de Sebastián de Segurola, con ocasión de su matrimonio con María Josefa Úrsula de Rojas y Foronda, en 1786. Son pocos los versos que aluden a esta circunstancia. En cambio, lo que ocupa la atención del poeta es la figura de Segurola como defensor de la ciudad, de cuya comandancia militar se había hecho cargo desde el 31 de diciembre de 1780 hasta el final de los asedios de Túpac Catari y de Túpac Amaru (octubre de 1781). A esto hace amplia referencia el extenso título, donde se indica que fue representada «en celebridad de los desposorios» mencionados, pero (y esto es lo relevante) "con ocasión de ser su principal asunto el de los acaecimientos experimentados en los dos cercos que sufrió en 1781 esta lastimera ciudad, en cuya defensa labró aquel señor su mayor mérito" 5 .

La lectura de la loa muestra la presencia de un esquema muy frecuente en este tipo de piezas: después de una introducción a cargo de la Música, que hace las veces de pregón que convoca al regocijo, un personaje alegórico llamado el Mérito manifiesta, en un largo parlamento, el motivo de la celebración. Entonces otros personajes alegóricos (en este caso los partidos de la provincia de La Paz) alternan en una puja en la que exponen, por turno y con algunas discusiones entre ellos, los motivos por los que cada cual considera que le corresponde el lugar preeminente en el festejo. Este tipo de pujas es frecuente en multitud de piezas del Siglo de Oro, muchos de cuyos elementos se mantuvieron vivos hasta los primeros años del siglo XIX. En la colección manuscrita de dieciocho piezas de teatro breve que encontramos en Potosí en 2002, que incluye nueve entremeses y varias loas (Arellano y Eichmann, 2005), el esquema descrito es seguido en algunas de ellas y alcanza una expresión magistral en el Coloquio de los Once Cielos (Eichmann Oehrli, 2003). 
En cuanto al asunto, la loa consigue condensar el inmenso y sangriento drama colectivo que se había vivido apenas cinco años antes (Eichmann Oehrli, 2012a y 2012b). En su largo parlamento de inicio, el Mérito se muestra decepcionado porque, según dice, suele correr triste "tras el premio mal hallado / pocas veces atendido, / muchas veces despreciado" (versos 38-40). Recuerda el temple y los esforzados trabajos de Segurola para la defensa de la ciudad de La Paz y para su posterior gobierno, y reclama de los partidos de la provincia una retribución en bendiciones, gratitud, obsequios y aplausos. Esto, junto con la puja de los partidos de la provincia, responde muy bien a lo que Suárez Radillo denomina "genuflexiones literarias” (citado por Zugasti, 1997: 563).

En su largo parlamento, el Mérito, al recordar el alzamiento indígena indica que el movimiento sedicioso

sacudió en estas provincias

el yugo más suave y caro

del gobierno y obediencia

que rendidos tributamos

al mayor de los monarcas

que por gran favor del cielo

se nos hubo deparado (versos 111-117)

Más adelante, muestra que es gracias a Segurola que pudieron los pobladores de La Paz sostenerse en los peligros y mantener su fidelidad al rey:

Decid, ciudad de La Paz, nobles y fieles vasallos del mejor de los monarcas; de Carlos Tercero, digo, de Carlos Tercero, el Sabio: ¿por quién tuviste tal brío?

¿Por quién, el valor ufano con que a un ¡Viva, viva el Rey!, en los mayores trabajos así te fortalecías de la muerte a los amagos? (versos 134-144)

Esto motiva la competencia entre los partidos, los cuales se ufanan de los dones que pueden aportar para celebrar a Segurola. Pero más adelante la competencia es frenada por la ciudad de La Paz, quien interviene, dirigiéndose a los partidos:

¿Capaces sois, por ventura, de dar a una heroica acción premio alguno? ¿Quién lo ignora?

Al mérito solo un señor absoluto y soberano puede dar digno valor. (versos 487-492) [...]

y como solo un Dios altísimo y poderoso saciar pueda el corazón del hombre, así en la tierra solo el rey, que en conclusión es su teniente y su imagen, llenar de satisfacción puede el mayor delos méritos (versos 498-505) [...]

y lo que debemos todos hacer en su galardón [de Segurola] no es ofrecerle riquezas porque el tesoro mayor (para nuestra gratitud, nuestro celo y nuestro amor) es poca cosa; y así 
lo que resta al corazón

es alegrar sus votos

para el Rey y para Dios. (versos 511-520)

Entre los teóricos españoles del teatro, García de Villanueva señala en 1788 que "el teatro es una escuela pública, donde con pretexto de entretenimiento asiste toda clase de ciudadanos a recibir lecciones de conducta" (Vieites, 2019: 210). Por su parte, para Leandro Fernández de Moratín, en un texto de 1787, el teatro contribuirá a "la corrección de las costumbres y, por consecuencia, a la estabilidad del orden civil" (Vieites, 2019: 211), en tanto que servirá para "suplir en gran parte los defectos de la falta de educación, de instruir al pueblo en lo que necesariamente debe saber, si ha de ser obediente, modesto, humano y virtuoso" (Vieites, 2019: 202). Explica además Vieites que el "nuevo canon dramático propone recrear otro mundo, el propio de una burguesía que quería hacer suyos conceptos como buen gusto y decoro" (Vieites, 2019: 211).

Tanto Moratín como Villanueva, en sus escritos, no hacen sino formular convicciones que ya estaban asentadas, y de las que también el poeta de La Paz parece hacerse eco, al menos en lo que supuso más necesario: consideró prudente reforzar los lazos de lealtad con el monarca en una ciudad en la que se habían producido expresiones y hechos sediciosos. Recordemos que ya en marzo de 1780 un pasquín llevaba la expresión "muera el rey de España” (Valle, 1990: 491), si bien en una construcción condicional, ya que añade: "si el monarca no sabe de las insolencias de sus ministros, de los robos públicos y cómo tienen hostilizados a los pobres, viva el rey y mueran todos estos ladrones". Y otro animaba a "sacudir el yugo de la obediencia a ejemplar de los colonos de cierta América (Valle, 1990: 500) a quienes considera admirables y dignos de memoria y envidia; hay que advertir que la autora considera "extraño y misterioso" este documento, que reproduceíntegro Lewin (1967: 722-724). Un año después llegó a La Paz la gran rebelión. Poco más tarde, en 1784, el arzobispo José Antonio de San Alberto presiente la circulación de una corriente que amenaza la sujeción al monarca (Gato Castaño, 2003: 83-85), y para poner remedio a ello compone un extenso Catecismo real, instrumento educativo destinado a su aprendizaje por parte de los fieles, sin olvidar, en particular, su uso en las escuelas. El contenido del Catecismo real no es novedoso, como no lo es tampoco el de los versos citados de la loa, puesto que la exaltación del rey es corriente ya en el Siglo de Oro. Pero es indudable la consonancia de ambos textos, escritos en el mismo espacio y con apenas una diferencia de dos años, destinados a medios con los que se contaba para orientar a la población, es decir escuela y teatro (no los únicos, por supuesto; puede añadirse, entre otros, el púlpito).

La pieza de San Alberto es acaso uno de los primeros catecismos políticos de la historia. De la misma década (1787) es el "Catéchisme du citoyen, ou Elemens du droit public français, par demandes \& réponses, suivi des Fragmens politiques, escrito por Joseph Saige", según registra Sotés Elizalde (2009: 204). De mucho interés es el texto de Javier Sáenz del Castillo Caballero, que analiza "la relación entre política y religión a través de la fundamentación última de la Soberanía, y esto en función de cuál sea la corriente doctrinal o 
ideológica" de cada catecismo político estudiado. Explica Sáenz que

\begin{abstract}
Al trasladar este recurso didáctico [nacido en el ámbito religioso] a la formación política, el nuevo mensaje, esta vez temporal en vez de espiritual, se reviste por analogía y mimetismo con su original de una autoridad más allá de lo que son opiniones humanas sobre cuestiones temporales, pues la gente se encuentra acostumbrada a que a través de esta pedagogía se expongan de manera irrefutable cuestiones dogmáticas de carácter sobrenatural y avaladas por la autoridad de una institución como es la Iglesia (Sáenz, 2010: 6).
\end{abstract}

El catecismo de San Alberto acude explícitamente a la autoridad de la religión para sustentar sus afirmaciones, para «recordar» a los vasallos la estrechísima obligación de: amar (Lección XII), temer (Lección XIV) y obedecer (LecciónXV) al rey, a quien deben fidelidad (Lección XVI), etc. (San Alberto, [1788] 2003, vol. 2: 11-62). El Catecismo real estuvo primero dirigido "a los niños y niñas criados en las Casas de Educación por él fundadas, [y] posteriormente [...] a todos los fieles, sin distinción de edad" (Gato Castaño, 2003: 86-87).

En la Carta circular y pastoral que San Alberto firma el 4 de marzo de 1790 y que dirige a todos los curas de la arquidiócesis para exhortarlos a que enseñen el Catecismo real, afirma que "los reyes son unas imágenes visibles de Dios, o unos Vicedioses suyos, que reinan en su lugar, y que en su nombre forman y promulgan leyes" (San Alberto, [1790] 2003, vol 2: 73). Explica Daisy
Rípodas que las ideas presentes en el Catecismo y en la Carta tienen su origen en Bossuet Politique tirée des propres paroles de l'Escriture Sainte (traducido y publicado en España en 1768 y 1789). La autora hace un muy interesante seguimiento de estas ideas, particularmente en Charcas, en concreto en el Catecismo de San Alberto (Rípodas, 1983: 97121) y en otro documento la Cartilla que en 1786 escribe el cura Martínez de Velasco, a pedido del gobernador de Moxos Lázaro de Ribera (conocedor del catecismo albertiano). Este documento, ya no inspirado en Bossuet sino simple plagio selectivo de él, se utilizó para adoctrinar políticamente a los indígenas mojeños, lo cual se realizaba "diariamente en las plazas de los pueblos después del rosario y memorizadas por los muchachos" (Rípodas, 1983: 114). Diez años más tarde Ribera lo entrega como obra propia para adoctrinar a los indígenas del Paraguay, su nuevo destino.

De haber tenido ocasión, San Alberto habría aplaudido sin reservas la loa. No sabemos hasta qué punto fueron cumplidas las órdenes del arzobispo. Sí podemos suponer que la loa tendría un alcance bastante efímero, dado que los pasajes citados fueron escuchados una vez, pudiendo ser dados al olvido muy rápidamente por el público allí presente. En cualquier caso, y vinculadas o no con estos textos, vemos aparecer expresiones semejantes a las del catecismo albertiano y a las de la loa en un documento escrito en La Paz en 1808, titulado Rasgos de la mayor lealtad, impreso en Lima apenas unos meses antes del alzamiento libertario. El documento, estudiado por Mario Castro Torres (2012), recoge noticias de la ciudad en torno a la celebración de la jura al rey Fernando VII (entonces cautivo), que incluyó 
diversos espectáculos y expresiones poéticas. En una "oda" leemos:

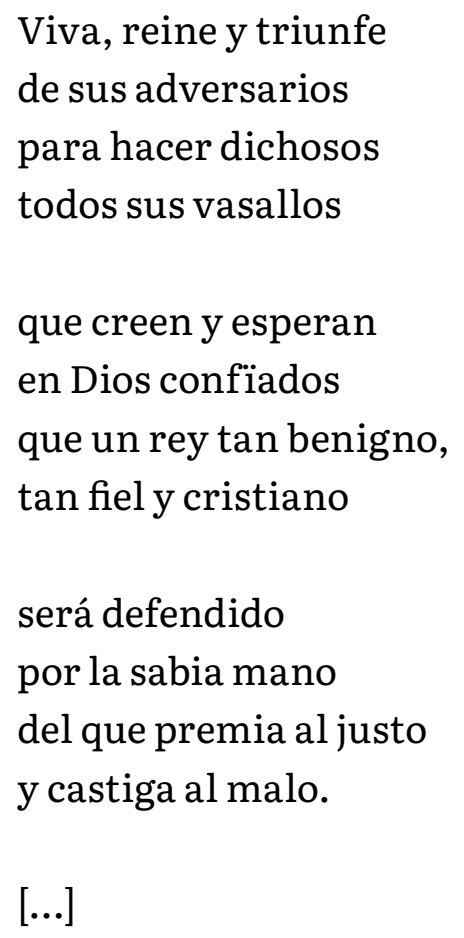

Para él, por la Patria

y Ley ofrezcamos

haciendas y vidas

en grato holocausto. (Anónimo, 1808: 16-17)

Para entonces, el absolutismo ilustrado convivía con otras propuestas políticas. Algunos pobladores de La Paz y otras ciudades estaban preparando hacía ya años la desvinculación de estos espacios de la Corona. En los mismos territorios de Charcas había otros, como Victorián de Villava, que buscaban a fines del siglo XVIII nuevas modalidades de relación con la metrópoli, a la vez que nuevas formas dentro del sistema monárquico. Lo que hemos visto aquí corresponde a la voz oficial, manifestada ya por convicción, por auténticos seguidores de las ideas de Bossuet, ya por interés, como el caso de Tadeo Fernández Dávila, que es quien (sigo el trabajo de Castro) promovió los festejos de La Paz como medio para que las autoridades se resolvieran a mantenerlo en el cargo de gobernador.

\section{b. Dos entremeses}

En la Biblioteca Central de la UMSA se conserva, en un cuaderno, el traslado de estas dos piezas de teatro breve ${ }^{6}$, escritas en España. El primero es El castigo de un celoso, del madrileño José Julián López de Castro (1723-1763), que ocupa los ocho primeros folios ${ }^{7} \mathrm{y}$ las primeras líneas del siguiente, el cual es numerado nuevamente como primero. Aquí es donde empieza (hasta el fol. 7r) el segundo entremés, de Antonio de Zamora (1665-1728), titulado Las conclusiones.

El castigo de un celoso explora un tema ya tradicional, abordado en "El viejo celoso, de Miguel de Cervantes, y en Los refranes del viejo celoso, tradicionalmente atribuido a Quevedo"; se trata de "la joven malcasada con un viejo, quien, arrastrado por unos celos enfermizos, somete a aquella a una vigilancia y encierro continuos" (Briante Benítez, 2019: 436-437). En el de López de Castro, además, no solo se satiriza la conducta despótica de Domingo (el vejete), quien pretende mantener encerrada en su casa a su joven esposa, sino también su hipocresía, ya que él sale con la excusa de que irá a hacer obras caritativas, pero en realidad va a cortejar a unas majas. Lucrecia, la esposa del viejo, es auxiliada por una vecina llamada Preciosa, y entre ambas se encargan de organizar el escarmiento de Domingo. Los entremeses de López de Castro «siguen muy de cerca la 
tradición dramática áurea, por su morfología y los temas a los que dan cabida, por los tipos sobre los que construye sus personajes y por los rasgos estilísticos que presentan», pero también incluyen «determinadas prácticas, costumbres o hábitos sociales propios de su tiempo (Briante Benítez, 2019:464). Por otra parte, el autor citado observa que López de Castro podría considerarse "como un eslabón más a tener en cuenta a la hora de reconstruir el difícil proceso de evolución desde el entremés hasta el sainete" (Briante Benítez, 2019: 467), por incluir sátira social.

El castigo de un celoso no es la única presencia de López de Castro en La Paz de aquellos años. Precisamente en la loa de Jacinto de Liévana, uno de los personajes, el partido de Caupolicán, se refiere a una divertida pieza titulada Arancel económico para mantener una casa en Madrid; y los días de guardar para las faltriqueras, y cita de ella una décima en alabanza del chocolate (Eichmann Oehrli, 2013: 65).

El otro entremés, titulado Las conclusiones, de Antonio de Zamora (1665-1728), posiblemente estrenado en 1695 en Madrid (Martín Martínez, 2005: 14), explora carnavalescamente los recursos del humor centrado en la parodia de un acto académico en el que los latines macarrónicos alternan con otros correctos pero traducidos disparatadamente, y donde los tecnicismos gramaticales y oratorios son objeto de interpretaciones absurdas, todo lo cual se remata con unos premios dignos de tales intervenciones, entre los cuales figura un freno de burro.
Si bien este entremés es más antiguo (fines del XVII) tuvo un éxito sostenido: Martín Martínez registra trece ediciones, nueve del siglo XVIII y dos de principios del XIX (Martín Martínez, 2005: 73-74). Su presencia en La Paz sería, entonces, un nuevo dato para dimensionar su difusión. Llama la atención el hecho de que se encuentre manuscrito, habiendo salido tantas veces impreso.

Sin duda esta pieza cumplía con el cometido de ofrecer al pueblo un entretenimiento «honesto», tal como enfatizan los documentos que hemos examinado, en contraposición con el ruinoso vicio del juego. Por otra parte, no desentona con las intenciones de enseñar (deleitando) al público; intenciones que fueron (aunque no en exclusiva) acogidas por la Ilustración, a su modo peculiar, según ya vimos.

\section{Final}

Los pocos documentos que se refieren a la práctica teatral en La Paz, tanto los referidos a la construcción del coliseo como las tres obras que allí se han conservado (una de ellas escrita en la misma ciudad, en 1786) permiten registrar, tanto en las autoridades como en los sectores más educados de la población, la adhesión al proyecto ilustrado. Esta adhesión no es un simple gesto, una pose impuesta por una moda. Por el contrario, en toda la extensión de los territorios sujetos a la Audiencia de Charcas comprobamos la presencia, en el último tramo del periodo colonial, de una gran cantidad de sujetos que llevan a cabo con prodigiosa energía y lucidez proyectos acordes con las ideas ilustradas. William Lofstrom traza 
algunas pinceladas sobre ese tiempo en América, al decir que

encontramos a fines de la era colonial sociedades, economías e instituciones que nos asombran por su vigor y originalidad, siendo un mestizaje de lo mejor que habían aportado ambos mundos.

Como ejemplo, podemos citar las reformas borbónicas del rey Carlos III, bajo el sistema de las Intendencias. Fue una reformulación atrevida, comprensiva y lógica del complejo sistema burocrático español evolucionado a través de siglos de experiencia imperial, que permitió a España gobernar lejanas tierras con relativa eficiencia y justicia. Otros testimonios del vigor y esplendor del periodo colonial tardío son las magníficas fortificaciones militares que fueron levantadas por ingenieros militares españoles para defender los puertos estratégicos del Callao, Cartagena de Indias, La Habana y San Juan de Puerto Rico.

También en el campo de la ingeniería y la arquitectura tenemos la magnífica Casa de la Moneda de Potosí y su impresionante maquinaria de acuñación, concluida en 1773 [...]. El esplendor del barroco europeo en la arquitectura y el arte también se trasladó al mundo hispano americano con vigor y originalidad, como lo atestiguan la misma Casa de la Moneda y algunos templos altoperuanos, incluyendo el proyecto de la iglesia del convento de Santa Teresa de Cochabamba, en cuyo trazo original [...] vemos[...] un diseño
[...] que se puede comparar a algunas obras de Borromini (Lofstrom 2003: 783-784).

Sería de mucho interés establecer, siquiera de modo aproximativo, un elenco de personajes que imprimieron el clima de ideas y acciones destacables de esos años: los intendentes Juan del Pino Manrique y Francisco de Paula Sanz, en Potosí, junto con Pedro Vicente Cañete y Domínguez, asesor de ambos; Francisco de Viedma, en Cochabamba; el naturalista Tadeo Haenke, indisociable de Viedma, al igual que el gobernador de Santa Cruz Seoane de los Santos; el gobernador de Mojos, Lázaro de Ribera; el ya mencionado fiscal Villava; el jurista Francisco Gutiérrez de Escobar, cuya obra tuvo un "fulgurante éxito en todas las Indias occidentales" (Thibaud, 2010: 18; para el contenido: 66-70); otro jurista, fundador en Potosí de la Academia de Minería y del Banco de San Carlos, Jorge Escobedo y Alarcón; el metalurgista José de Suero González y Andrade; en el ámbito eclesiástico, el arzobispo San Alberto (en estas páginas no nos hemos ocupado de sus destacables contribuciones y logros: es el primero que pone en marcha colegios en cinco ciudades, también para niñas, novedad absoluta para entonces), el franciscano Antonio Comajuncosa, el canónigo Matías Terrazas, y tantos otros (para los aquí señalados, remito a Barnadas, 2002; algunos de ellos son tratados con algún detalle en Barnadas, 2010). Aunque tal cosa excede los límites de este trabajo, vale la pena señalar que este es el contexto en el que actuó, como vimos al principio, el intendente interino de La Paz, también ilustrado y convencido de la viabilidad y de los beneficios para la población del proyecto compartido. Fernando de la Sota Agüero, a la par que se ocupa del orden, de la infraestructura y del ornato de la ciudad de 
La Paz, se encarga también de la construcción del coliseo, buscando ponerlo al servicio de la corrección de las costumbres y para evitar los daños del juego y los crímenes nocturnos.

Laactividad teatral también responde ajustadamente al proyecto ilustrado. Es concebida, a la par de la escuela, como instrumento útil para la educación del pueblo. Las enseñanzas que se imparten en él pueden llegar al auditorio directamente, a través del contenido mismo, transmitido desde la escena por el parlamento de un personaje que se considera digno de estima, o bien de manera indirecta, al poner en ridículo determinadas formas de pensar y actuar. La primera de ambas modalidades la hemos visto al servicio de la «educación cívica», con la que se pretendía despertar el afecto y la sumisión al monarca. Se ha podido comprobar, además, su consonancia con los contenidos cívicos que se inculcaron en elámbito escolar (y también extraescolar) mediante el sistema de repetición de preguntas y respuestas del Catecismo real del arzobispo San Alberto. Las afirmaciones según las cuales el rey es el representante de Dios, de quien proviene la autoridad que detenta, aparecen en ambos textos. Dos décadas más tarde, en los versos compuestos para la gran celebración paceña de la jura de fidelidad a Fernando VII, a mediados de octubre de 1808 , vemos de nuevo asociado al monarca con la mano de Dios. En esa solemne jura, las "manifestaciones de regocijo" incluyeron "procesiones, danza, poesía y teatro" (Castro Torres, 2012: 405). No nos han llegado las expresiones teatrales, que al parecer solo consistieron en algunas mojigangas (Castro Torres, 2012: 419) para satisfacer el gusto popular, seguramente porque estas no fueron consideradas dignas de atención por parte de quien envió a Lima el texto titulado Rasgos de la mayor lealtad para que fuera impreso. Esta exclusión también podría resultar esperable en quien tuviera un paladar formado en la Ilustración.

\section{Referencias citadas}

Siglas de archivos citados (y sus secciones)

\section{ALP Archivo de La Paz \\ AGI Archivo General de Indias}

\section{RL Rockefeller Library}

UMSA Universidad Mayor de San Andrés

Acosta, N. ([1880] 2019): Guía del viajero en La Paz, La Paz, Fondo Editorial Municipal Pensamiento Paceño

Anónimo del siglo XVIII (1901): Anales del Cuzco. 1600 a 1750 (prólogo de Ricardo Palma) Lima, Imprenta del Estado

Anónimo del sigloXIX (2012): Rasgos de la mayor lealtad, extraídos de un Diario de la Ciudad de Nuestra Señora de La Paz desde que se supo la Proclamación del Señor Don Fernando VII hasta que se solemnizó el Juramento de Fidelidad, Mario Castro Torres (ed.), Anuario. Estudios Bolivianos Archivísticos y Bibliográficos, 18, pp. 407-422

Aranzáes, N. ([1915] 2019): Diccionario histórico del Departamento de La Paz, La Paz, Fondo Editorial Municipal Pensamiento Paceño. 
Arellano, I. y A. Eichmann Oehrli (2005): Entremeses, loas y coloquios de Potosí (Colección del Convento de Santa Teresa), Madrid/Frankfurt, Universidad de Navarra/ Iberoamericana/Vervuert

Barnadas, J. M., Dir. (2002): Diccionario Histórico de Bolivia, 2 vols., Sucre, Grupo de EstudiosHistóricos

Barnadas, J. M., (2010): «Breve paseo por la Ilustración en Charcas», Sucre, Archivo y Biblioteca Nacionales de Bolivia, en Memoria del Coloquio. El pensamiento universitario de Charcas y el 25 de Mayo de 1809 y 1810, pp. 23-42

Briante Benítez, F. J. (2019): “La producción entremesil de José Julián López de Castro", Estudios de literatura, 10, pp. 430-475

Cárdenas Piedra, E. de (1995): Caballeros de la Orden de Santiago. Siglo XVIII (Continuación de la obra de Vicente Cadenas y Vicent, del mismo título, que quedó interrumpida en el tomo V), T. VII, Años 1789-1799, números 2074 al 2393, Madrid, Ediciones Hidalguía

Castro Torres, M. (2012): "Un documento olvidado de 1808: los "Rasgos de la mayor lealtad, extraídos de un Diario de la ciudad de nuestra Señora de La Paz desde que se supo la proclamación del señor don Fernando hasta que se solemnizó el juramento de fidelidad"”, Anuario. Estudios Bolivianos Archivísticos y Bibliográficos, 18, pp. 387-422

Diez de Medina (1994): Diario del alzamiento de indios conjurados contra la ciudad de Nuestra Señora de La Paz, 1781, María Eugenia del Valle (ed.), La Paz, Banco Boliviano Americano.
Eichmann Oehrli, A. (2003): "El Coloquio de los Once Cielos. Una obra de teatro breve del Monasterio de Santa Teresa (Potosí)", Historia y Cultura, 28-29, pp. 95-132.

Eichmann Oehrli, A. (2012a): "Diatribas contra el enemigo caído en una loa de La Paz (1786)", en Poderes y autoridades en el Siglo de Oro. Realidad y representación, Lourenço, A. A. y J. M. Usunáriz (eds.), Pamplona, EUNSA, pp. 43-58

Eichmann Oehrli, A. (2012b): "Incas y caudillos en dos piezas teatrales: o de los hechos al papel”, en Imagen del poder. Memoria del VI Encuentro Internacional sobre el Barroco, La Paz, Fundación Visión Cultural, pp. $265-275$

Eichmann Oehrli, A. (2013): “Teatro breve y brevísimo en el sur andino", Bulletin of the Comediantes, 65 , 2, pp. 57-67

Gato Castaño, P. (2003): “Introducción”, en José Antonio de San Alberto, Obras completas, 2 vols., ed. de Purificación Gato Castaño, Burgos, Editorial Monte Carmelo, vol. I, pp. 21-111

Gisbert, T. (1962): Teatro virreinal en Bolivia, La Paz, Biblioteca de Arte y Cultura (Serie Letras, 1)

Lewin, B. (1967): La rebelión de Túpac Amaru y los orígenes de la independencia de Hispanoamérica, Buenos Aires, S.E.L.A.

Lofstrom, W. (2003): “Un singular texto matemático potosino de 1816”, en Anuario, Archivo y Biblioteca Nacionales de Bolivia, pp. 781-808.

Martín Martínez, Rafael(2005): “Noticia Bibliográfica”, 
en A. de Zamora, Teatro breve (Entremeses), Madrid/ Frankfurt, Iberoamericana/Vervuert, pp. 71-83.

Rípodas Ardanaz, D. (1983): La refracción de ideas en Hispanoamérica colonial, Buenos Aires, Ediciones Culturales Argentinas, Secretaría de Cultura.

Sáenz del Castillo Caballero, J. (In Press): Política y religión en los catecismos políticos durante la independencia de América, 1786-1825, 2010. Disponible en https:// www.researchgate.net/publication/257044993_IN_ PRESS_Politica_y_religion_en_los_catecismos_politicos_durante_la_independencia_de_America_1786-1825 (fecha de consulta: 31-07-2019)

San Alberto, J. A. de (2003): Obras completas, 2 vols., Edición, Introducción y notas de P. Gato Castaño, Burgos, Editorial Monte Carmelo

Sotés Elizalde, M. A. (2009): “Catecismos políticos e instrucción política y moral de los ciudadanos (siglos XVIII y XIX) en Francia y España”, Educación, XX1 (12), pp. 201-218.

Thibaud, C. (2010): La Academia Carolina y la independencia de América. Los abogados de Chuquisaca (17761809), Sucre, Editorial Charcas / Fundación Cultural del Banco Central de Bolivia/ Archivo y Biblioteca Nacionales de Bolivia.

Valle, M. E. del (1990): Historia de la rebelión de Tupac Catari. 1781-1782, La Paz, Editorial Don Bosco.

Vieites, M. (2019): “Ilustración, educación y teatro en España a finales del siglo XVIII. Algunas claves", Espacio, Tiempo y Educación, 6 (1), 2019, pp. 199-224. doi: http://dx.doi.org/10.14516/ete.1942019
Zamora, A. de (2005): Teatro breve (Entremeses), Edición de Rafael Martín Martínez, Madrid / Frankfurt, Iberoamericana / Vervuert

Zugasti, M.(1997): “Un texto virreinal inédito: Loa para la zarzuela también se vengan los dioses de Lorenzo de las Llamosas", en Unum et diversum. Estudios en honor de Ángel-Raimundo Fernández González, Pamplona, EUNSA, pp. 553-589

\section{Notas}

1AGI, Estado, 76, núm. 2 y AGI, Charcas, 436, fol. 450.

${ }^{2}$ Estuvieron en proceso de restauración hasta hace poco. Actualmente el Archivo se encuentra cerrado a causa de la pandemia.

${ }^{3}$ Me encaminó a esta pieza la lectura de T. Gisbert (1962: 8).

4En el ALP, RE, año 1786, fol. 19 (sin numerar) aparece su firma, al igual que en varios otros documentos de la misma caja; véase por ejemplo en el tercer cuaderno, titulado Registro cuarto, los folios 19, 35, 40 y 44 (sin numerar), donde aparece a la izquierda la firma de Crespo y, a su derecha, la de Liévana.

${ }^{5}$ El título varía según el testimonio manuscrito que se consulte. Cito aquí según el que se encuentra en el volumen de la RL, Colección Church, signatura 1-Size zqF B65. Los datos de este párrafo los tomo de Eichmann Oehrli, 2012a, p. 44.

${ }^{6}$ Colección José Rosendo Gutiérrez, núm. 2318.

${ }^{7}$ El fol. 3v está en blanco. 